\title{
Las reglas generales de contratación electrónica en la Ley 30/2007,de Contratos del Sector Público
}

\author{
Eduardo Gamero Casado \\ Profesor Titular de Derecho Administrativo \\ Universidad Pablo de Olavide de Sevilla
}

\begin{abstract}
SUMARIO: 1.- INTRODUCCIÓN. 1.1.- La contratación electrónica en la Era de la Información. 1.2.- Antecedentes normativos. 2.- LA CONTRATACIÓN ELECTRÓNICA EN LA LEY DE CONTRATOS DEL SECTOR PÚBLICO. 2.1.- Sistemática del cuerpo legal en materia de contratación electrónica. 2.2.Integración del sistema de fuentes en materia de contratación electrónica. 3.CONTRATACIÓN ELECTRÓNICA Y RESERVA DE LEY. 3.1.- La reserva de Ley en la imposición de la contratación electrónica. 3.2.- Necesidad de desarrollo reglamentario de la contratación electrónica por parte de las diferentes administraciones públicas. 4.- EL PRINCIPIO DE NO DISCRIMINACIÓN Y SUS MANIFESTACIONES. 5.- REQUISITOS DE SEGURIDAD, CONFIDENCIALIDAD, INTEGRIDAD Y CONSERVACIÓN. EN PARTICULAR, EL USO OBLIGATORIO DE LA FIRMA ELECTRÓNICA RECONOCIDA. 5.1.Requisitos generales. 5.2.- La imposición de la firma electrónica reconocida. 6.- OTRAS REGLAS GENERALES EN LA CONTRATACIÓN ELECTRÓNICA. 6.1.- Incidencias en la presentación de documentos. 6.2.- El formato de los documentos presentados. 6.3.- Inscripción obligatoria de datos en el Registro Oficial de Licitadores y Empresas Clasificadas. 7.- LA FACTURA ELECTRÓNICA. 8.- CONCLUSIÓN
\end{abstract}

\section{INTRODUCCIÓN. CONTEXTO Y ANTECEDENTES DE LA CONTRATACIÓN ELECTRÓNICA}

\subsection{La contratación electrónica en la Era de la Información}

En este trabajo analizamos cómo se regula la contratación electrónica en la Ley 30/2007, de 30 de octubre, de contratos del sector público (en lo sucesivo, LCSP), a cuyo fin ceñimos la exposición a las reglas generales de contratación electrónica contenidas en las Disposición adicional 19a y en la Disposición final $9^{a}$ de la Ley, sin abordar el estudio de otros muchos aspectos en que 
este cuerpo legal incide en la cuestión, como los registros telemáticos de contratistas, los perfiles de contratante, la subasta electrónica, los sistemas dinámicos de contratación, o la plataforma de contratación del Estado, que por su carácter específico desbordan el objeto de nuestra aportación.

Como fundadamente sostiene CASTELLS ${ }^{1}$, durante el último cuarto del siglo XX la sociedad ha modificado radicalmente sus estructuras dando lugar a un nuevo período histórico, conocido como Era de la Información, y caracterizado por el uso de las tecnologías de la información y la comunicación. No es posible entrar aquí en detalle a exponer los indicadores y las consecuencias de este cambio en la sociedad en general ${ }^{2}$, ni tampoco ilustrar las concretas repercusiones que está derivando específicamente para el Derecho administrativo y la Administración pública (dando lugar a la llamada Administración electrónica $)^{3}$. Pero sí conviene aportar unos pocos datos significativos que evi-

\footnotetext{
${ }^{1}$ Sostiene el autor que se ha producido una transformación de magnitud equivalente a la que supuso en su día la máquina de vapor, desencadenante de la revolución industrial y, correlativamente, de la Edad Moderna. Véase CASTELLS, M.: La Era de la Información. La sociedad red, Madrid, 1997.

${ }^{2}$ Para lo que debe acudirse a la obra citada, y a algunos informes relativos al grado de implantación de la Sociedad de la Información en España, como los elaborados por Eurostat, accesibles en http://epp.eurostat.ec.europa.eu; el estudio España 2007. Informe anual sobre el desarrollo de la Sociedad de la Información, elaborado por la Fundación Orange y accesible en http:/ / www.fundacionorange.es/areas/25_publicaciones/e2007.pdf; o el informe La Sociedad de la Información en España, de la Fundación Telefónica, accesible en http://www.telefonica.es/sociedaddelainformacion/html/informes_home.shtml .

${ }^{3}$ En relación con las consecuencias que entraña la implantación de la Administración electrónica en el Derecho administrativo véanse especialmente PIÑAR MAÑAS, J.L.: "Revolución tecnológica, Derecho administrativo y Administración pública", en La autorización administrativa. La Administración electrónica. La enseñanza del Derecho administrativo hoy, Cizur Menor (Navarra), 2007; GAMERO CASADO, E. y VALERO TORRIJOS, J. (Coords.): La Ley de Administración electrónica. Comentario sistemático a la Ley 11/2007, de 22 de junio, de acceso electrónico de los ciudadanos a los Servicios Públicos, Cizur Menor (Navarra), 2008; VALERO TORRIJOS, J.: El régimen jurídico de la e-Administración, Granada, 2007; BARNÉS VÁZQUEZ, J.: "Una reflexión introductoria sobre el Derecho administrativo y la Administración pública de la sociedad de la información y del conocimiento", Revista Andaluza de Administración Pública, ${ }^{\circ}$ 40, 2000; PUNZÓN MORALEDA, J. (coord.): Administraciones públicas y nuevas tecnologías, Valladolid, 2005; PALOMAR OLMEDA, A.: La actividad administrativa efectuada por medios electrónicos, Cizur Menor (Navarra), 2007; y BERNADÍ GIL, X.: "Derecho público y Administración electrónica: una visión panorámica”, Nuevas políticas públicas. Anuario multidisciplinar para la modernización de las Administraciones públicas, $\mathrm{n}^{\circ}$ 1, 2005.
} 
dencian hasta qué punto se ha transformado la sociedad y las exigencias que ello proyecta hacia el Derecho administrativo y la gestión administrativa.

Por una parte, en la campaña del IRPF, cuatro millones y medio de declaraciones se presentaron por vía telemática ${ }^{4}$, cifra que también se alcanza en las declaraciones de aduanas ${ }^{5}$. Y en lo que se refiere a la Seguridad Social, el 97'38\% de los movimientos de afiliación (cerca de 62 millones de operaciones) han tenido lugar a través de Internet (sistema CIR-RED), realizándose el $95^{`} 46 \%$ de los pagos por medios electrónicos ${ }^{6}$. Un último dato significativo es que el portal del Boletín Oficial del Estado recibe más de dos millones de visitas diarias, sin que nadie recuerde ya prácticamente la existencia de una edición en papel que, por otra parte, ha desaparecido desde 1 de enero de $2009^{7}$, debido, precisamente, a su inutilidad.

Estos datos son elocuentes por sí solos del grado de implantación de las nuevas tecnologías en la vida cotidiana y en la gestión administrativa. Evidencian, por otra parte, que cuando se ofrecen servicios de calidad por medios electrónicos y telemáticos la sociedad los utiliza masivamente. La consecuencia que de ello se deriva para el tema en examen es que la contratación electrónica no constituye en la actualidad un simple cauce de mejora en la gestión administrativa o un signo ornamental de modernidad, sino que representa además un medio para facilitar los trámites a las empresas contratistas y para agilizar la gestión de los procesos implicados en la contratación. Desde esta perspectiva, la generalización de la contratación electrónica es una verdadera exigencia para un Estado de Derecho que desee situarse a la altura de la sociedad a la que sir-

\footnotetext{
${ }^{4}$ El último dato disponible corresponde al ejercicio de 2006 (declaraciones presentadas en 2007); cfr. http://www.aeat.es/AEAT/Contenidos_Comunes/La_Agencia_Tributaria/Tramites_on_Line/Otros_Servicios/ESTADISTICAS/Declaraciones_presentadas_por_Internet/estadinet31012008.pdf (consultada el 31/1/08).

${ }^{5}$ Ibidem, donde se expone que en el ejercicio de 2007 se presentaron cerca de cuatro millones y medio de DUAs de exportación y poco más de cuatro millones de DUAs de importación.

${ }^{6}$ Véase la Memoria de actuaciones de la Tesorería General de la Seguridad Social correspondiente a 2006 (última disponible), en http:/ /www.seg-social.es , sección "Estadísticas e Informes", pestaña "Documentación".

${ }^{7}$ Véase el Real Decreto 181/2008, de 8 de febrero, de ordenación del diario oficial "Boletín Oficial del Estado", dictado en desarrollo del art. 11.2 y la Disposición Final 2 de la Ley 11/2007.
} 
ve (la Sociedad de la Información) y de su tiempo coetáneo (la Era de la Información), como vienen advirtiendo otros autores ${ }^{8}$.

Claro exponente de ello es la generalización de la contratación electrónica en el sector privado: en 2007, el comercio electrónico alcanzó el 50 \% del total $^{9}$, en un crecimiento exponencial que evidencia la madurez de estos canales de contratación ${ }^{10}$. Importa notar que gran parte de este éxito encuentra su origen en la decidida apuesta de la Unión Europea por la expansión de la contratación electrónica privada, cuyo régimen jurídico goza de mayor tradición que en el ámbito público. Como recordaremos más tarde, un importante elemento para el impulso de la Administración electrónica es la seguridad jurídica, siendo preciso establecer legalmente los medios y tecnologías utilizables y reconocer el valor jurídico de su empleo. Esto es lo que hizo la Unión Europea con directivas de impulso a la contratación electrónica y lo que ha respaldado España con su trasposición, acumulándose en el día de hoy un importante acervo normativo (principalmente, la Ley 34/2002, de 11 de julio, de servicios de la sociedad de la información y de comercio electrónico, recientemente modificada por la Ley 56/2007, de 28 de diciembre, de medidas de impulso de la sociedad de la información) sobre el comercio electrónico que sin duda contribuyen a generalizar su empleo, despejando cualquier duda jurídica que pudiera suscitar el uso de estos medios de contratación. A esta tarea también ha contribuido sin duda la aportación doctrinal, que afronta no sólo los aspectos estrictamente regulados por la Ley, sino que se extiende al conjunto de cuestiones implicadas en el comercio electrónico, desplegando

\footnotetext{
${ }^{8}$ Véase DOMÍNGUEZ-MACAYA LAURNAGA, J.: "La adopción por los poderes adjudicatarios de la contratación electrónica: una tarea inaplazable", Contratación administrativa práctica, $\mathrm{n}^{\circ} 41$, 2005, págs. 37 y sigs.; y, con mayor amplitud de contenidos, "La e-contratación. Presente y futuro de la contratación electrónica", en VV.AA.: Contratación del sector público local, La Ley-El Consultor, Madrid, 2008, pp. 2085 ss. El autor estructura sus argumentos aportando y distinguiendo entre razones de índole legal, de tipo económico y de carácter estratégico.

${ }^{9}$ Según los datos recogidos en el Informe sobre el comercio electrónico en España a través de entidades de medios de pago correspondiente al segundo trimestre de 2007, realizado y hecho público por la Comisión del Mercado de las Telecomunicaciones en marzo de 2008, La cifra total de negocio del comercio electrónico en España alcanzó un nuevo récord en el segundo trimestre del pasado año, con un total de 938 millones de euros, un 47\% más que el mismo periodo de 2006.

${ }^{10}$ Una minuciosa exposición de experiencias comparadas de contratación electrónica, con especial atención por las enclavadas en el sector público, en DOMÍNGUEZ-MACAYA LAURNAGA, J.: "La e-contratación...", op.cit., pp. 2135 ss.
} 
una tarea de integración e interpretación que a partir de ahora también resulta precisa en el sector público ${ }^{11}$.

En cambio, como expresivamente señala REGO, la contratación pública "a diferencia de su hermana de Derecho privado, ha vivido prácticamente ajena a los beneficios de las nuevas tecnologías de la información y la comunicación (TICs) hasta hace muy poco. La razón de esta situación es casi de carácter ontológico, pues los principios y reglas que rigen la contratación del sector público (publicidad, libre concurrencia y no discriminación) impiden que las Administraciones públicas puedan contratar como un particular más, acudiendo a las webs en que las distintas empresas ofrecen sus productos y servicios en la red. Sin embargo, la incorporación de nuevas tecnologías al ámbito de la contratación pública presenta la ventaja de reforzar de forma muy importante los principios jurídicos en que ésta se apoya, y simultáneamente, a los sujetos contratantes les alivia considerablemente las dificultades que supone someterse a las exigencias de un procedimiento administrativo de contratación"12.

En relación con la contratación pública o public procurement, la Unión Europea observó tempranamente la utilidad de las nuevas tecnologías, promoviendo la generalización de la contratación electrónica en dos esferas distintas y complementarias de intervención: las iniciativas de impulso a la Administración electrónica y el Derecho comunitario de la contratación administrativa.

En lo que se refiere al primer ámbito, la comunicación de la Comisión El papel de la Administración electrónica en el futuro de Europa ${ }^{13}$ declara que el impulso de

${ }^{11}$ Como simple orientación acerca de este extremo pueden verse SOLER MATUTES, P. (dir): Manual de gestión y contratación informática. Comentarios, jurisprudencia actualizada, formularios de contratos comentados y modelos oficiales del COEIC, Cizur Menor (Navarra), 2006, especialmente págs. 319 y sigs.; MADRID PARRA, A. (dir.): Derecho patrimonial y tecnología, Madrid, 2007, págs. 117 y sigs.; CAMACHO CLAVIJO, S.: Partes intervinientes, formación y prueba del contrato electrónico, Madrid, 2005; VEGA VEGA, J.A.: Contratos electrónicos y protección de los consumidores, Madrid, 2005; PLAZA PENADÉS, J.: "El marco jurídico de la contratación electrónica”, Revista Aranzadi de Derecho y Nuevas Tecnologías, $\mathrm{n}^{\circ}$ 4, 2004, págs. 19 y sigs.; BARRIUSO RUIZ, C.: La contratación electrónica, Madrid, 2006; BLASCO GASCÓ, F.P. (dir.): Contratación y nuevas tecnologías, Madrid, 2005; y VV.AA.: Notariado y contratación electrónica, Madrid, 2000. En el Derecho comparado, es de especial interés la consulta de LISI, A. (coord.): I contratti di Internet, Milano, 2006.

12 Cfr. REGO BLANCO, M.D.: "Las nuevas tecnologías en la futura Ley de Contratos del Sector Público”, en MADRID PARRA, A. (dir.): Derecho patrimonial..., op.cit., pág. 624,

${ }^{13}$ COM (2003) 567 final, de 26 de septiembre; comunicación no publicada en el Diario Oficial, accesible en http://europa.eu/scadplus/leg/es/s21012.htm\#APPROCHE 
la Administración electrónica constituye una decisión estratégica de la Unión Europea, percibiendo, en particular, que el procedimiento tradicional de contratación es complejo, largo y costoso, debiendo reemplazarse por medios electrónicos.

Mayor recorrido tienen estas políticas en el régimen jurídico-comunitario de la contratación administrativa. El primer antecedente reside en la Comunicación de la Comisión conocida como Libro verde de la contratación pública europea ${ }^{14}$. Este texto constituye el primer documento en el que se plasma un impulso oficial a la contratación electrónica por parte de la Unión Europea, dando lugar poco después a la inclusión de esta cuestión en una propuesta normativa ${ }^{15}$, origen de la Directiva 2004/18/CE (como es sabido, la necesidad de su trasposición es lo que ha llevado a la aprobación de la Ley 30/2007), en la que se regulan ciertos aspectos de la contratación electrónica pública, ampliamente comentados ya desde el ámbito doctrinal ${ }^{16}$.

Para entender mejor la visión subyacente en la Directiva sobre el tema en examen conviene centrarse en primer término en la Comunicación de la Comisión

${ }^{14}$ COM (96) 583 final, de 27 de noviembre; comunicación no publicada en el Diario Oficial, accesible en http://europa.eu/publicprocurement/index_es.htm

${ }^{15}$ COM (2000) 275 final, de 10 de mayo; comunicación no publicada en el Diario Oficial, accesible en http://eur-lex.europa.eu/LexUriServ/LexUriServ.do?uri=CELEX:52000PC0275:EN:NOT

${ }^{16}$ Véanse MESTRE DELGADO, J.F.: "La subasta electrónica: consideraciones sobre el empleo de medios telemáticos en la contratación pública”, Revista General de Derecho Administrativo, n 2, 2003, págs. 1 y sigs. (trabajo que aborda con carácter general el empleo de las nuevas tecnologías en la contratación administrativa, sin restringir el análisis a la subasta electrónica); GALLEGO CÓRCOLES, I.: "Contratación pública electrónica", en PUNZÓN MORALEDA, J. (coord.): Administraciones públicas y nuevas tecnologías, Valladolid, 2005, págs. 219 y sigs.; MEDINA ARNÁIZ, T.: "La contratación pública electrónica: balance actual de su regulación en Europa", en GALINDO AYUDA, F. (coord.): Gobierno, Derecho y tecnología: las actividades de los poderes públicos, Cizur Menor (Navarra), 2006, págs. 527 y sigs.; GIMENO FELÍU, J.M.: "La utilización de las nuevas tecnologías en la contratación pública", Documentos de trabajo (repositorio de documentos electrónicos sostenido por la Facultad de Derecho de la Universidad de Zaragoza y accesible en http://dteconz.unizar.es), $\mathrm{n}^{\circ}$ 2004-3, págs. 1 y sigs.; PUNZÓN MORALEDA, J. y SÁNCHEZ RODRÍGUEZ, F.: "El uso de las nuevas tecnologías en la Administración pública: la contratación pública electrónica prevista en la Directiva 2004/18/CE", en Revista de Derecho de las telecomunicaciones e infraestructuras en red, $\mathrm{n}^{\circ}$ 24, 2005, págs. 63 y sigs.; DOMÍNGUEZ-MACAYA LAURNAGA, J.: "La contratación electrónica en el Proyecto de Ley de Contratos del Sector Público. Análisis y propuestas de mejora", Contratación administrativa práctica, $\mathrm{n}^{\circ}$ 62, 2007, págs. 49 y sigs.; del mismo autor, "La adopción...", op.cit., págs. 37 y sigs. 
Plan de acción para la aplicación del marco jurídico de la contratación electrónica de 13 de diciembre de $2004^{17}$. En el documento se expresa que la implantación de la contratación pública electrónica supondría ahorro del $5 \%$ del gasto y entre el 50-80\% del coste de operaciones, de tal manera que, si se alcanza el propósito de generalizar los procedimientos electrónicos de contratación en el año 2010, el ahorro estimado sería de 19 billones de euros ${ }^{18}$. Sin embargo, la Unión Europea percibe ciertos peligros en el uso de las nuevas tecnologías para la contratación, pues existen complicaciones técnicas graves, como la interoperabilidad (compatibilidad entre los medios electrónicos del poder público contratante y el sector privado), la accesibilidad y el principio de no discriminación (especialmente focalizado en la brecha digital, o falta de disponibilidad de las tecnologías en ciertas capas sociales), que dificultan la implantación de la contratación electrónica. Estos inconvenientes chocan además con el mercado interior en la medida que impedirían a ciertas empresas (las que carecen de estos recursos) competir con las demás. Por ello, la directriz seguida por la Unión Europea en esta materia (y así se ha reflejado en la Directiva 2004/18), es dejar a los Estados libertad para decidir con qué intensidad implantan soluciones de contratación electrónica, limitándose pues a establecer un mínimo régimen normativo que introduzcan en esta materia la seguridad jurídica necesaria para que los diferentes ordenamientos nacionales puedan desarrollar tales previsiones sin temor a que resulten incompatibles con el Derecho comunitario.

Este contexto subyacente es el que explica la regulación de la contratación electrónica en la Directiva 2004/18, que constituye, por otra parte, el primer texto normativo que regula la contratación electrónica en la Unión Europea, toda vez que los documentos anteriores carecen de fuerza de obligar ${ }^{19}$. Sus objetivos principales en la materia que nos ocupa $\operatorname{son}^{20}$ :

17 Documento no publicado en el Diario Oficial, accesible en http://ec.europa.eu/internal_market/publicprocurement/e-procurement_en.htm Dispone de un texto de desarrollo -Extended Impact Assesstment-, sólo en versión inglesa, accesible en el mismo lugar.

18 Datos referidos a UE-15 miembros.

19 Cabe indicar, por otra parte, que la Directiva cuenta con un documento interpretativo específicamente relativo a la contratación electrónica: Requirements for conducting public procurement using electronic means under the new public procurement Directives 2004/18/EC and 2004/17/EC, SEC(2005) 959, de 8 de julio de 2005; documento no publicado en el Diario Oficial, sólo disponible en versión inglesa y accesible en la URL indicada en la nota anterior.

${ }^{20}$ La Directiva, además de estas consideraciones generales, regula materialmente algunos aspectos sectoriales o específicos de la contratación electrónica, como las subastas electrónicas (art. 54) o los sistemas dinámicos (art. 33), que son objeto de comentario en otros lugares de esta obra. 
1. Reconocer jurídicamente las comunicaciones electrónicas dándoles carta de naturaleza. En este sentido, y análogamente a lo que ya ha ocurrido en relación con el comercio electrónico privado, la Directiva pretende introducir seguridad jurídica en el empleo de las nuevas tecnologías en la contratación, lo que constituye una vía indirecta (pero evidente) para promover el impulso de la contratación electrónica, al conseguir un aumento de la confianza de las partes.

2. Igualar el soporte electrónico a los documentos en papel, concediendo plena validez jurídica a los documentos electrónicos ${ }^{21}$.

Estas determinaciones normativas se establecen por la Directiva dejando plena libertad a los Estados para implantar escenarios de contratación electrónica en los tempos que cada uno de ellos decida, lo cual es coherente con lo antedicho acerca de la no obstaculización del mercado interior y la superación progresiva de la brecha digital, de acuerdo con los principios de igualdad de trato, no discriminación y transparencia ${ }^{22}$.

\subsection{Antecedentes normativos}

Esta materia no se encontraba inicialmente regulada en la Ley de Contratos de las Administraciones Públicas. No obstante, el Reglamento General

${ }^{21}$ Lo que en otro contexto he calificado como principio de equivalencia de soportes; véase GAMERO CASADO, E.: "Objeto, ámbito de aplicación y principios generales de la Ley de Administración electrónica; su posición en el sistema de fuentes”, en GAMERO CASADO, E. y VALERO TORRIJOS, J. (coords.): La Ley de Administración electrónica. Ley 11/2007, de 22 de junio, de acceso electrónico de los ciudadanos a los Servicios Públicos, Cizur Menor (Navarra), 2008, págs. 100 y sigs.

${ }^{22}$ A tal efecto son ilustrativos los comentarios realizados en los considerandos 12 a 16 de la Directiva; especialmente, en considerando 12 se dice que: "Se están desarrollando constantemente nuevas técnicas electrónicas de compra. Dichas técnicas permiten ampliar la competencia y mejorar la eficacia del sistema público de pedidos, en particular mediante el ahorro de tiempo y dinero que entraña la utilización de las mismas. Los poderes adjudicadores pueden utilizar técnicas electrónicas de compra, siempre que su utilización se realice dentro del respeto de las normas establecidas en la presente Directiva y de los principios de igualdad de trato, no discriminación y transparencia"; y en el 16 se afirma que: "Para tener en cuenta las diversidades existentes en los Estados miembros, conviene dejar a estos últimos la opción de prever la posibilidad de que los poderes adjudicadores recurran a acuerdos marco, a centrales de compras, a sistemas dinámicos de adquisición, a subastas electrónicas y al diálogo competitivo, según quedan definidos y regulados por la presente Directiva". 
de la Ley de Contratos, aprobado mediante Real Decreto 1908/2001, articuló en su Disposición Adicional 10 a una autorización al Ministerio de Economía y Hacienda para regular la contratación electrónica ${ }^{23}$.

Como consecuencia de esta autorización se han dictado diferentes textos reglamentarios. El que más directamente afecta a la materia objeto de comentario es la Orden EHA/1307/2005, de 29 de abril, por la que se regula el empleo de medios electrónicos en los procedimientos de contratación: gran parte de los contenidos de la Disposición adicional 19 LCSP encuentran su origen en dicha Orden ministerial ${ }^{24}$.

Las novedades sustanciales que aporta la LCSP en esta materia, por tanto, son la elevación del rango de la regulación, que de estar contenida en una mera Orden ahora pasa a tener rango de Ley; y en el carácter básico que se confiere al precepto ${ }^{25}$, que determina su aplicación a todas las Administraciones públicas y no sólo a la Administración del Estado como sucedía con anterioridad.

También existen antecedentes en materia de contratación electrónica en el Derecho autonómico, siendo especialmente significativo el régimen esta-

23 Esta Disposición establece: "Procedimientos de contratación mediante el empleo de medios electrónicos. Se autoriza al Ministerio de Hacienda para que por Orden ministerial establezca las normas que regulen los procedimientos para hacer efectiva la contratación mediante el empleo de medios electrónicos". La validez de esta remisión de segundo grado a normas reglamentarias subordinadas no encontraba encaje en la propia LCAP, beneficiándose tácitamente de la deslegalización que contenía la Disposición Adicional $18^{\mathrm{a}}$ de la Ley 30/1992, como tendremos ocasión de exponer con más detalle cuando comentemos un poco más adelante la Disposición Final $19^{a}$ de la LCSP.

${ }^{24}$ Con fundamento en la misma remisión reglamentaria se dictaron otras disposiciones cuya conexión material con el tema que tratamos es más limitada: la Orden EHA/1744/2005, por la que se establecen las condiciones generales, formularios y modelos para la presentación y tramitación telemáticas de solicitudes de clasificación de empresas, y se aprueba la aplicación telemática para su tratamiento; y la Orden EHA/1077/2005, por la que se establecen los formatos y especificaciones de los medios informáticos y telemáticos para la remisión de datos de contratos al Registro Público de Contratos.

25 Véase la Disposición final 7. 
blecido en el País Vasco ${ }^{26}$. Menos extenso, pero igualmente valioso, es el Decreto catalán 96/2004, de 20 de enero, por el que se regula la utilización de los medios electrónicos, informáticos y telemáticos en la contratación de la Administración de la Generalidad.

\section{LA CONTRATACIÓN ELECTRÓNICA EN LA LEY DE CONTRA- TOS DEL SECTOR PÚBLICO}

\subsection{Sistemática del cuerpo legal en materia de contratación electrónica}

Como recuerda su Exposición de Motivos (§ IV.3), la LCSP apuesta "por la plena inserción de los medios electrónicos, informáticos y telemáticos en el ámbito de la contratación pública, a fin de hacer más fluidas y transparentes las relaciones entre los órganos de contratación y los operadores económicos". Sin embargo, lo hace de manera fragmentaria y además diseminada a todo lo largo de su texto, por lo que conviene, en primer término, aclarar de qué manera regula la Ley la contratación electrónica.

La LCSP ha modificado la sistemática tradicional en nuestro Derecho sobre la regulación de la contratación administrativa, decidiéndose por un modelo de tipo secuencial que se encuentra esencialmente estructurado a partir del procedimiento de contratación: preparación de los contratos (Libro II); selección del contratista y adjudicación (Libro III); y efectos, cumplimiento y extinción (Libro IV). Existen algunas disposiciones previas y finales comunes a toda la materia (Título preliminar y Libros I y V), pero la sistemática elegida es regular las diferentes cuestiones que concurren en la contratación pública a medida que se abordan las diferentes fases del procedimiento de contratación. En esta nueva sistemática la contratación electrónica no ha encontrado un encaje unitario, desglosándose su regulación en dos vertientes distintas:

\footnotetext{
${ }^{26}$ Articulado alrededor de la Orden de 16 de agosto de 2004, de la Consejera de Hacienda y Administración pública, sobre tramitación telemática de determinados procedimientos y actuaciones previstas en la legislación de contratos de las Administraciones públicas $\left(B O P V \mathrm{n}^{\circ} 164\right.$, de 27 de agosto). La disposición sigue estando vigente en la actualidad, y ha sido objeto de una amplia aplicación práctica. Para conocer todos los pormenores resultará de interés la consulta del portal de contratación electrónica del Gobierno Vasco, accesible en http://www.contratacion.info
} 
1. La determinación de un régimen general del uso de las nuevas tecnologías en la contratación administrativa, que tiene lugar en la Disposición Adicional 19 (en lo sucesivo, DA 19) que ahora comentamos.

2. La regulación de aspectos específicos de la contratación electrónica ${ }^{27}$, como la creación y mantenimiento por parte de todo el sector público de un perfil de contratante que constituye, cuando menos, un instrumento de publicidad a través de Internet, aunque puede asumir otros contenidos y erigirse en un verdadero "interfaz" para el conjunto de cuestiones implicadas en la contratación administrativa de los sujetos del sector público (art.42); la presentación por medios electrónicos, informáticos o telemáticos de certificaciones de inscripción en el registro de licitadores y empresas clasificadas (arts.72.3 y 130.3); la presentación de garantías por los contratistas por medios electrónicos (art.85.3); la reducción de los plazos en el procedimiento urgente de contratación cuando el anuncio de licitación se envíe por medios electrónicos, informáticos o telemáticos (art.97.2.b); la publicación alternativa del anuncio previo de contratación en el Diario de la Unión Europea o en el perfil de contratante (art.125.228); la subasta electrónica (art.132); la acreditación de la aptitud para contratar mediante presentación de los correspondientes certificados por medios electrónicos, informáticos y telemáticos (art.135.4); la reducción de los plazos mínimos para las actuaciones cuando se estén utilizando medios electrónicos, informáticos o telemáticos, lo que se refleja en diferentes lugares del texto legal ${ }^{29}$, y muy señaladamente en el plazo de presentación de proposiciones, que se reduce en 40 días (de 45 a 5) cuando se ofrezca acceso por medios electrónicos a los pliegos y a la documen-

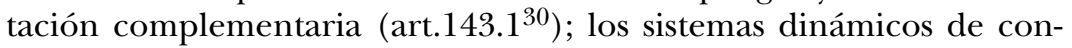

\footnotetext{
${ }^{27}$ Para un análisis más detenido de todas estas cuestiones remitimos a los comentarios de los correspondientes artículos en esta misma obra.

${ }^{28}$ Cuando el anuncio se realiza de esta manera, los arts.150.2 y 151.1 establecen, además, que en la invitación cursada a los candidatos en el procedimiento restringido no tiene que incluir un ejemplar de los pliegos ni copia de la documentación complementaria, bastando con permitir el acceso a estos documentos por medios electrónicos, informáticos o telemáticos.

${ }^{29}$ Véanse, por ejemplo, los arts. 148.1 y 250.4.

${ }^{30}$ Que establece asimismo otras reducciones de plazos cuando se empleen estos medios.
} 
tratación, que constituye de hecho un procedimiento paralelo de contratación íntegramente desarrollado por medios electrónicos, informáticos y telemáticos (arts.183 y sigs.); la gestión electrónica, informática y telemática del Registro de Contratos del Sector Público (art.308); la Plataforma de Contratación del Estado (art.309); las comunicaciones electrónicas y telemáticas en el procedimiento de contratación (DA 18); y las facturas electrónicas (DF 9ª).

Aquí nos corresponde estudiar específicamente la DA 19, que establece las reglas generales de la contratación electrónica, sin perder de vista el sistema normativo en el que se encuadra la cuestión.

Ante todo, llama la atención el lugar elegido por el legislador para llevar a cabo la regulación de la contratación electrónica: a pesar de que enfáticamente -como ya hemos visto- se declara partidario de generalizar los medios electrónicos, informáticos y telemáticos en la contratación administrativa, destierra el régimen marco de la materia a un lugar tan recóndito como una disposición adicional, por lo demás extensa y deficientemente estructurada, que decepciona extraordinariamente en su contenido y no contribuye, ciertamente, a la puesta en valor de la materia. Entiendo que hubiera sido deseable incluir esta cuestión en alguno de los bloques normativos legales consagrados a la regulación de aspectos generales, y en particular, el Libro V de la Ley, donde hubiera recibido perfecto encaje y donde hubiera podido verse acompañada, además, de algunos otros preceptos legales poco afortunados en su actual ubicación sistemática, como la DA 18 o la DF 9.

El propio Consejo de Estado lamentó en su informe al Anteproyecto de Ley el tratamiento que se confería a esta cuestión, que sin embargo no ha sido mejorada sustancialmente con ocasión de sus trámites parlamentarios. El alto cuerpo consultivo sostuvo -a mi juicio, acertadamente-, que: "Otros aspectos necesitados de mejora son todos los relativos a la contratación electrónica, ya sea que recaigan sobre el entero proceso de contratación (sistemas dinámicos), ya únicamente sobre la licitación (subasta electrónica) o ya, en fin, sobre cualesquiera medios a emplear en el procedimiento de selección y adjudicación (comunicaciones por medios electrónicos)"31.

31 Véase el Informe del Consejo de Estado de 25 de mayo de 2006 (Número de expediente: 514/2006), sobre el Anteproyecto de Ley de Contratos del Sector Público, apartado XII, letra C). No obstante, el dictamen no se pronuncia después concretamente sobre las DA 18 y 19 del Anteproyecto, sin explicitarse pues los motivos de insatisfacción del Consejo de Estado acerca de su contenido. 
En particular, el carácter fragmentario de esta regulación, y el recóndito lugar en el que se ha recogido, puede forjar en los operadores la errónea impresión de que lo único que cabe hacer en materia de contratación electrónica es aquello que la Ley regula expresamente. Nada menos cierto. La LCSP, coherentemente con la Directiva que traspone, es neutra en cuanto a la imposición de la contratación electrónica al conjunto de Administraciones públicas, y se limita a formular algunos fogonazos o regulaciones-marco (en los términos anteriormente indicados), sin prejuzgar la opción de los diferentes operadores del sector público por la tramitación integral de los procedimientos de contratación en soporte electrónico. Buena prueba de ello es la existencia de regímenes generales de contratación electrónica incluso antes de la aprobación de la LCSP ${ }^{32}$.

Creo, no obstante, que si verdaderamente pretendía promover la contratación electrónica, el legislador debería haber sido más pedagógico y suministrar al conjunto de operadores jurídicos un régimen completo del procedimiento de contratación aunque sea con carácter no básico. Al no optar por esta fórmula, da la impresión de que sólo cabe hacer por medios electrónicos, informáticos o telemáticos aquello que el legislador regula expresis verbis, cuando en realidad todo el procedimiento de contratación puede ser tramitado por estos medios, siempre que se lleve previamente a cabo su regulación por parte de cada Administración pública, como trataré expresamente más abajo.

Por ejemplo, la Ley no dice que los concursos, o los procedimientos negociados, puedan tramitarse por medios electrónicos, cuando es perfectamente posible que se haga así. En ninguna parte se afirma tampoco que los órganos colegiados de contratación pueden celebrar sus reuniones por medios telemáticos, cuando esta posibilidad resulta completamente lícita en la actualidad. Y así sucesivamente. Quiero decir que todo lo relativo a la contratación administrativa, actualmente, puede bascular hacia el soporte digital y desterrar para siempre la gestión en soporte papel, tanto en el plano interno administrativo como en las relaciones con el sector privado, y que, de hecho, la Ley lo reconoce -implícitamente- así, pero, a juzgar por el modo en que regula la cuestión... inadie lo diría!

\footnotetext{
32 Véanse las disposiciones dictadas en esta materia por el Ministerio de Economía y Hacienda, y por el Departamento de Hacienda del País Vasco, ambas citadas en el primer apartado de este trabajo.
} 
En materia de contratación electrónica el objetivo a lograr es que los procedimientos se tramiten íntegramente en soporte electrónico y se proceda a la desaparición del papel ${ }^{33}$, un propósito que no es mera especulación y que se hará inevitablemente realidad en un horizonte relativamente próximo. Para lograrlo, esta Ley hace sus aportaciones, pero no es suficiente, pues quedan huérfanos de regulación aspectos relevantes de la materia, lo que a su vez provoca en los operadores jurídicos la sensación de que la incorporación de las nuevas tecnologías a la contratación administrativa constituye un elemento coadyuvante o auxiliar en determinados aspectos del procedimiento o en circunstancias particulares (subastas electrónicas, sistemas dinámicos, publicidad...). No obstante, la progresiva materialización de estas novedades legales demostrará su aptitud y sus enormes ventajas, favoreciendo además la formación (un aspecto nuclear en esta materia) y la familiarización de todos los operadores con las nuevas tecnologías en su aplicación a la contratación administrativa. Será entonces cuando se demuestre la relativa facilidad con la que pueden introducirse los cambios y la enorme ventaja que representa su implantación. En ese momento se hará patente la necesidad de una regulación más prolija y asistiremos a una inevitable reforma legal o a un desarrollo reglamentario de la materia conforme a las delegaciones normativas que la Ley establece, y se percibirá el conjunto de cuestiones implicadas en la contratación electrónica, que habrán de ser objeto de regulación específica: licitaciones, notificaciones, formalización del contrato, acceso electrónico al expediente, remisión a los órganos judiciales... En espera de ese momento, hemos de apañarnos con los escasos mimbres que trenza la LCSP y las disposiciones reglamentarias antecedentes, y restringir a ellos nuestro comentario.

\subsection{Integración del sistema de fuentes en materia de contratación electrónica}

Otra importante percepción en el modo en que la LCSP regula la contratación electrónica es la absoluta falta de referencias en esta materia a la Ley 11/2007, de 22 de junio, de acceso electrónico de los ciudadanos a los Servicios Públicos (en lo sucesivo, LAE), también conocida como Ley de Administración electrónica. Apenas unos meses separan ambos cuerpos legales, pero el legislador de contratos ha acometido su tarea desde una reluciente campana de cristal, sin otear alrededor ni conciliar su texto con el de otras disposiciones con las que guarda una estrecha conexión material. Reconociendo la

33 Las virtudes que encierra este tránsito han sido excelentemente expuestas por DOMÍNGUEZ-MACAYA LAURNAGA, J.: "La ieContratación, una nueva -y necesaria- forma de entender la contratación administrativa”, Contratación administrativa práctica, nº 53, 2005, págs.34 y sigs. 
elevada calidad técnica general de la LCSP, es sencillamente increíble que esta concreta cuestión haya recibido semejante trato: no sólo se omite toda referencia expresa a la prelación del sistema de fuentes que debe presidir la confluencia de ambas disposiciones, es que además la LAE es mucho más rica, versátil y adecuada para la regulación de ciertos temas que la LCSP, y en lugar de apoyarse en su texto y remitir al mismo, se lleva a cabo una regulación especial que la desplaza y depara desafortunados efectos, como hemos de ver más adelante.

Importa notar que la LAE "regula los aspectos básicos de la utilización de las tecnologías de la información en la actividad administrativa, en las relaciones entre las Administraciones Públicas, así como en las relaciones de los ciudadanos con las mismas con la finalidad de garantizar sus derechos, un tratamiento común ante ellas y la validez y eficacia de la actividad administrativa en condiciones de seguridad jurídica" (art.1), y que resulta aplicable a todas las Administraciones territoriales y a las entidades de derecho público vinculadas o dependientes de las mismas (art.2), por lo que también resulta de aplicación a dichos sujetos en materia de contratación administrativa siempre que se utilicen medios electrónicos, informáticos o telemáticos. La primera cuestión a despejar en esta materia es, por tanto, la prelación del sistema de fuentes, identificando cómo se engarzan en su aplicación los diferentes textos normativos concurrentes.

Para ello debe aplicarse la teoría general de la especialidad normativa, siendo perfectamente posible, como recuerda la doctrina, que una norma que es especial en su relación con una norma general, sea al propio tiempo ley general para un tercer cuerpo normativo, dándose una sucesión de círculos concéntricos en las relaciones de generalidad y especialidad que puede extenderse a lo largo de varios textos legales sucesivos ${ }^{34}$. En este sentido, la LAE es especial respecto de la Ley 30/1992 en lo que se refiere al empleo de medios electrónicos, informáticos y telemáticos por las entidades incluidas en su ámbito de aplicación, pero a su vez la LCSP contiene unas previsiones más especiales en materia de contratación electrónica que desplazan el contenido de la LAE, erigiendo a esta última en ley general en la materia respecto de la LCSP, de tal manera que la escala en la prelación de fuentes sería la siguiente:

${ }^{34}$ Véanse especialmente MONDUGNO, F.: "Norme singolari, speciali, eccezionali”, en Enciclopedia del diritto, Milano, 1978, pág.514; y DÍEZ-PICAZO, L.M.: La derogación de las leyes, Madrid, 1990, pág. 345. 
1. Las normas especiales sobre contratación electrónica contenidas en la LCSP. Esta posición se encuentra expresamente revalidada por la DA $4^{a}$ LAE, que salva la especialidad de la legislación específica de contratación electrónica ${ }^{35}$.

2. Las normas contenidas en la LAE, que tratándose de Ley especial en materia de Administración electrónica, y general por lo que se refiere específicamente a la contratación electrónica, son de aplicación en tanto que no entren en conflicto normativo (antinomia) con la LCSP. Este segundo nivel normativo nos será de enorme utilidad en punto a la interpretación e integración de la LCSP, pues debido a sus claros déficit de normación, resulta preciso completar sus disposiciones con el régimen general de Administración electrónica contenido en la Ley $11 / 2007$, lo que permite conferir coherencia a muchos postulados de la LCSP y concretar además el alcance y los efectos de muchas de sus determinaciones, como iremos viendo a lo largo del trabajo.

3. Las normas generales de contratación administrativa (esto es, el resto de la LCSP), por tratarse de una materia especial respecto de la gestión administrativa general.

4. La legislación administrativa general (Ley 30/1992 y restantes textos de aplicación), de carácter supletorio respecto de la legislación de contratos administrativos.

En términos generales no se producen colisiones o antinomias entre estas normas jurídicas, pero sí nos será muy útil esta prelación, y en particular, la invocación de la Ley 11/2007, como ya se ha dicho, para integrar las cuestiones relativas a la contratación electrónica insuficientemente reguladas por la Ley 30/2007.

\footnotetext{
${ }^{35}$ Dice la DA $4{ }^{a}$ LAE: "en la aplicación de esta ley habrán de ser tenidas en cuenta las especificidades en materia de contratación pública, conforme a lo preceptuado en la disposición adicional séptima del Texto Refundido de la Ley de Contratos de las Administraciones Públicas, aprobado por Real Decreto Legislativo 2/2000, de 16 de junio". Aunque la referencia se efectúe a la legislación anterior, debe entenderse que ahora opera sobre la Ley 30/2007.
} 


\section{CONTRATACIÓN ELECTRÓNICA Y RESERVA DE LEY}

\subsection{La reserva de Ley en la imposición de la contratación electrónica}

La pregunta que nos planteamos en este punto es: ¿puede imponerse por la Administración pública o poder adjudicador necesaria y exclusivamente el uso de medios electrónicos, informáticos y telemáticos a los particulares en materia de contratación administrativa, inadmitiendo pues las comunicaciones dirigidas en soporte papel? La pregunta, realmente, no es específica en materia de contratación electrónica, sino genérica para todos los ámbitos relacionados con la Administración electrónica, y ha sido ya sobradamente tratada por la doctrina.

El empleo de medios electrónicos, informáticos y telemáticos por las Administraciones públicas en su giro o tráfico interno no se encuentra sometido a reserva de ley, pero cuando se pretende imponer a los ciudadanos que necesariamente usen esos medios para realizar sus gestiones administrativas sí existe esa reserva, que deriva de la "reserva general de ley respecto de todos los actos del poder público que incidan de modo limitativo en la esfera jurídica o personal de los ciudadanos" ${ }^{36}$, y que la LAE ha acogido expresamente en su art.27.1, aunque ya se observaba la vigencia de este principio con anterioridad a su aprobación ${ }^{37}$.

Esta reserva de ley se salva por la propia LCSP en los artículos citados más arriba que expresamente regulan el empleo de medios electrónicos, informá-

\footnotetext{
${ }^{36}$ Cfr. SANTAMARÍA PASTOR, J.A.: Fundamentos de Derecho administrativo, Madrid, 1988, págs. 781 y sigs., quien sintetiza brillantemente la situación existente en España acerca del principio de reserva de ley, materia en la que pueden consultarse igualmente BAÑO LEÓN, J.M.: Limites constitucionales a la potestad reglamentaria, Madrid, 1991, págs. 199 y sigs.; REBOLLO PUIG, M.: "Juridicidad, legalidad y reserva de ley como límites a la potestad reglamentaria del Gobierno", Revista de Administración Pública, ${ }^{\circ}$ 125, 1993, págs. 97 y sigs.; y BELADÍEZ ROJO, M: "La vinculación de la Administración al Derecho", Revista de Administración Pública, $\mathrm{n}^{\circ}$ 153, 2000, págs. 333 y sigs.

37 Véanse especialmente VALERO TORRIJOS, J.: El régimen..., op.cit., págs. 49 y sigs.; REGO BLANCO, M.D.: "Registros, comunicaciones y notificaciones electrónicas", en GAMERO CASADO, E. y VALERO TORRIJOS, J.: La Ley de Administración electrónica, op.cit., págs. 391 y sigs.; mi propia aportación en esa misma obra, págs. 93 y sigs.; GÓMEZ PUENTE, M: "La Administración...", op.cit., págs. 123 y sigs. y 127 y sigs.; COTINO HUESO, L: "Derechos del ciudadano administrado e igualdad ante la implantación de la Administración electrónica”, RVAP, n ${ }^{\circ} 68,2004$, págs. 141 y sigs.
} 
ticos y telemáticos. Pero como ya se ha visto, la regulación que lleva a cabo esta Ley sobre la contratación electrónica es fragmentaria y parcial. Se trata por tanto de saber qué sucede en el caso de que se desee extender el régimen de la contratación electrónica a espacios más amplios de los expresamente previstos. En este sentido, diferentes preceptos establecen las correspondientes habilitaciones reglamentarias que suponen una técnica de remisión normativa con su correlativa descongelación de rango.

En primer lugar, el art.27.6 LAE reconoce una vía general, aplicable por todas las Administraciones públicas para implantar la Administración electrónica (y por consiguiente, también la contratación electrónica) articulando una remisión normativa expresa, en los siguientes términos: "Reglamentariamente, las Administraciones Públicas podrán establecer la obligatoriedad de comunicarse con ellas utilizando sólo medios electrónicos, cuando los interesados se correspondan con personas jurídicas o colectivos de personas físicas que por razón de su capacidad económica o técnica, dedicación profesional u otros motivos acreditados tengan garantizado el acceso y disponibilidad de los medios tecnológicos precisos". No parece que la opción de obligar a las comunicaciones electrónicas pueda suscitar alguna duda en materia de contratación administrativa, habida cuenta de la necesidad de que los contratistas tengan acreditada su capacidad como requisito previo a la contratación, y encontrándose generalizado el uso de las nuevas tecnologías en el sector empresarial español como se desprende de los datos estadísticos que he aportado el inicio de este comentario ${ }^{38}$. El precepto encuentra su antecedente en la Disposición Adicional $18^{\mathrm{a}}$ de la Ley 30/1992 -introducida por la Ley 24/2001-, y supone un ejemplo de remisión normativa de la ley al reglamento en materias reservadas a la ley, permitiendo que por vía reglamentaria se imponga el uso obligatorio de los medios electrónicos, informáticos y telemáticos a determinados sujetos cualificados. De hecho, antes de la reforma de 2001 era una práctica extendida la imposición de comunicaciones telemáticas en ámbitos sectoriales, lo que fue pacíficamente aceptado por la doctrina ${ }^{39}$.

Además, la DF 9 LCSP, que comentaremos más tarde, "autoriza al Ministro de Economía y Hacienda para aprobar, previo dictamen del Consejo de Es-

\footnotetext{
${ }^{38}$ En la misma opinión, MESTRE DELGADO, J.F.: "La subasta electrónica...”, op.cit., pág. 24.

${ }^{39}$ Véase AGIRREAZKUÉNAGA ZIGORRAGA, I. y CHINCHILLA MARÍN, C.: "El uso de medios electrónicos, informáticos y telemáticos en el ámbito de las Administraciones públicas", $R E$ $D A, \mathrm{n}^{\circ} 109,2001$, págs. 51 y sigs.
} 
tado, las normas de desarrollo de la disposición adicional decimonovena que puedan ser necesarias para hacer plenamente efectivo el uso de medios electrónicos, informáticos o telemáticos en los procedimientos regulados en esta Ley". Además, por lo que específicamente respecta a las comunicaciones utilizables en materia de contratación administrativa, la DA 18 LCSP dispone que "Las comunicaciones e intercambios de información que deban efectuarse en los procedimientos regulados en esta Ley podrán hacerse, de acuerdo con lo que establezcan los órganos de contratación o los órganos a los que corresponda su resolución, por correo, por telefax, o por medios electrónicos, informáticos o telemáticos".

\subsection{Necesidad de desarrollo reglamentario de la contratación electrónica por parte de las diferentes administraciones públicas}

La conclusión más evidente que deriva de lo antedicho es la necesidad de que las diferentes Administraciones públicas procedan a un desarrollo normativo en materia de contratación electrónica que complete la regulación parcial que la LCSP lleva a cabo en esta materia. Sólo de este modo se introducirá la necesaria seguridad jurídica en la tramitación integral de procedimientos de contratación por medios electrónicos, informáticos y telemáticos. Esta competencia normativa corresponde a todas las Administraciones públicas y ha de extenderse también a los poderes adjudicadores que carezcan de la condición estricta de tales, quienes habrán de recibir la oportuna cobertura normativa a través de sus correspondientes administraciones matrices.

El desarrollo normativo en cuestión no es técnicamente complejo, y puede superarse con extraordinaria facilidad. Algunos ejemplos perfectamente emulables son las disposiciones citadas en el primer apartado de este comentario: la Orden EHA/1307/2005, de 29 de abril, por la que se regula el empleo de medios electrónicos en los procedimientos de contratación, y la Orden de 16 de agosto de 2004, de la Consejera de Hacienda y Administración pública del País Vasco, sobre tramitación telemática de determinados procedimientos y actuaciones previstas en la legislación de contratos de las Administraciones públicas.

Una fórmula extraordinariamente versátil para la operatividad de la contratación electrónica es introducir en estas disposiciones una remisión normativa de segundo grado, estableciendo que el alcance del empleo de los medios electrónicos, informáticos, y telemáticos en el correspondiente procedimiento de contratación se establecerá caso por caso, conforme a lo que se determine en el pliego de cláusulas administrativas particulares del contrato: es 
la opción seguida por la Orden ministerial citada ${ }^{40}$, que encuentra expreso respaldo, por lo demás, en la DA 18 LCSP. De este modo, según cuál sea la naturaleza del contrato a licitar, y su previsible universo de licitadores, la Administración pública (o poder adjudicador) podrá aquilatar el empleo de las nuevas tecnologías haciendo una oportuna ponderación de los intereses en presencia: de un lado, la eficiencia en la gestión, y de otro, el principio de libre competencia.

\section{EL PRINCIPIO DE NO DISCRIMINACIÓN Y SUS MANIFESTA- CIONES}

Las tres primeras letras del apartado 1 de la DA 19 pueden agruparse bajo la genérica acepción del principio de no discriminación, que se expresa en tres manifestaciones específicas según el ámbito material sobre el que se proyecta. Así, la letra a) proclama un principio de no discriminación sobre los canales (medios) que se utilicen en la contratación electrónica; la letra b), sobre la información disponible acerca de las licitaciones y el hardware exigible para formular ofertas; y la letra c), sobre el software (programas y aplicaciones) necesarios para la presentación de ofertas y solicitudes.

Todo ello encuentra regulación paralela en la Ley de Administración electrónica -especialmente, arts.4 b) y 4.i)-, habiendo sido la materia sobradamente analizada e interpretada con anterioridad a su acogida en la LCSP ${ }^{41}$.

En relación con lo primero (Administración multicanal), es preciso insistir en la necesidad de ofrecer a los ciudadanos plataformas y cauces telemáticos diferentes mediante los que realizar sus comunicaciones. En este sentido, el Anexo de la Ley de Administración electrónica define a los canales como "Estructuras o medios de difusión de los contenidos y servicios; incluyendo el canal presencial, el telefónico y el electrónico, así como otros que existan en la actualidad o puedan existir en el futuro (dispositivos móviles, TDT, etc.)".

\footnotetext{
${ }^{40}$ Si bien dicho texto señala que la utilización de los medios electrónicos, informáticos y telemáticos será potestativa para los licitadores, que por consiguiente serían libres de optar por mantener sus comunicaciones en soporte papel.

41 Véanse especialmente COTINO HUESO, L.: "Derechos...”, op.cit., págs. 139 y sigs.; VALERO TORRIJOS, J.: El régimen..., op.cit., págs. 56 y sigs.; BERNADÍ GIL, X.: "Derecho público...", op.cit., págs. 230 y sigs.; y PALOMAR OLMEDA, A.: La actividad..., op.cit., págs.98 y sigs.
} 
Obviando la deficiente estructura sistemática y gramatical que se ha conferido a estas disposiciones, es llano que con ellas se pretende evitar que la Administración electrónica se limite a utilizar un solo cauce de comunicación (Internet) y propicia el ofrecimiento de servicios multicanales. Las estadísticas disponibles en España sobre este aspecto son demoledoras ${ }^{42}$.

En relación con el resto de manifestaciones del principio de no discriminación, subyace en la LCSP (coherentemente además con la Ley de Administración electrónica), una prelación vinculante para las Administraciones públicas, que deberán utilizar preferentemente estándares abiertos y, solo de forma complementaria, otros estándares, que habrán de ser, además, de uso generalizado por los ciudadanos: así, la Administración puede facilitar al ciudadano los programas necesarios para realizar los trámites electrónicos, pero en todo caso, tanto la conexión como dichos programas habrán de ser compatibles con, al menos, las dos aplicaciones informáticas más extendidas entre los usuarios. El Anexo de la LAE define al estándar abierto como aquel que reúna las siguientes condiciones: 1) Sea público y su utilización sea disponible de manera gratuita o a un coste que no suponga una dificultad de acceso; y 2) Su uso y aplicación no esté condicionado al pago de un derecho de propiedad intelectual o industrial.

La plena operatividad de este principio plantea grandes complicaciones. Por ejemplo, algunas Administraciones se ciñen a programas comerciales -sistema operativo Windows ${ }^{\circledR}$ y navegadores como Explorer $^{\circledR}$ - sin facilitar versiones compatibles con el software libre o gratuito, en tanto que otras funcionan precisamente con programas libres. -sistema operativo Linux ${ }^{\circledR}$, navegador Mozilla ${ }^{\circledR}$...-. Existen razones de fondo que explican ambas opciones y justifican la independencia en la elección de alternativas incluida en el principio de neutralidad tecnológica: en cuanto al software libre, su menor coste económico y la disponibilidad de los códigos fuente, que concede el control absoluto de la aplicación a la Administración y evita que la empresa comercial introduzca en el programa códigos espía u otras prácticas indebidas; en cuanto a los programas comerciales, su mayor implantación real entre los usuarios. Pero todo esto, a su vez, provoca problemas de interoperabilidad entre las diferentes Administraciones públicas y grandes limitaciones a los ciudadanos. Una

\footnotetext{
${ }^{42}$ Así, el $94 \%$ de los sitios censados admite como dispositivo de acceso únicamente el ordenador personal. Un $5 \%$ son accesibles mediante PDA y un 2\% lo son mediante WAP (telefonía móvil) y tan solo a un $1 \%$ es posible acceder a través de telefonía fija. Fuente: Informe IRIA 2006, accesible en http://www.csi.map.es/csi/iria2006.
} 
vez más sería deseable la convergencia de todas las Administraciones hacia esfuerzos comunes, desarrollando aplicaciones aptas para todo tipo de sistema operativo y sus correspondientes programas asociados ${ }^{43}$.

\section{REQUISITOS DE SEGURIDAD, CONFIDENCIALIDAD, INTE- GRIDAD Y CONSERVACIÓN. EN PARTICULAR, EL USO OBLI- GATORIO DE LA FIRMA ELECTRÓNICA RECONOCIDA}

\subsection{Requisitos generales}

La DA 19, apdo.1, letra d) LCSP relaciona una serie de exigencias de seguridad, integridad, confidencialidad y conservación, con expresa mención de los virus informáticos, problemas que no son específicos de la contratación electrónica ni de la Administración electrónica en general, sino comunes a todo ámbito de gestión en que se implanten los medios electrónicos, informáticos y telemáticos. Se trata de articular una serie de soluciones tecnológicas que impidan el acceso malintencionado a la información, que garanticen la no alteración de los documentos electrónicos dejando huellas o trazas en el caso de que alguien modifique su contenido, que acrediten la identidad del receptor sin que además éste pueda negar que recibió un mensaje electrónico, y del emisor sin que tampoco él pueda negar que lo remitió, y así sucesivamente ${ }^{44}$.

Es obvio que el tipo de soluciones tecnológicas que se implanten en cada momento dependerá del estado de la ciencia y de la técnica, debiendo preservarse los principios jurídicos elementales (por ejemplo, en materia de autenticidad de la autoría de los documentos), y procurando evitar unas exigencias desorbitadas que impidan la implantación de la contratación electrónica. El desarrollo reglamentario será quien deba afrontar tales problemas y ofrecer soluciones ponderadas.

\footnotetext{
${ }^{43}$ Véase cuanto expongo en relación con esta cuestión en GAMERO CASADO, E.: "Objeto...", op.cit., págs. 97 y sigs.; y las aportaciones en materia de interoperabilidad de CERRILLO MARTÍNEZ, A.: "Cooperación entre Administraciones públicas para el impulso de la Administración electrónica”, en GAMERO CASADO, E. y VALERO TORRIJOS, J. (coords.): La Ley de Administración electrónica, op.cit., págs. 497 y sigs.

${ }^{44}$ Para ampliar el estudio de la cuestión remito la excelente obra colectiva SOLER MATUTES, P. (dir.): Manual de gestión y contratación informática, citada, en particular a sus dos primeras Partes (págs. 55 y sigs., y 177 y sigs. Sobre el particular problema de los virus informáticos en la contratación administrativa, véase especialmente DOMÍNGUEZ-MACAYA LAURNAGA, J.: "La e-contratación...", op.cit., pp. 2284 ss.
} 
En nuestro Derecho, el principal instrumento mediante el que se ha consensuado y determinado las exigencias técnicas aplicables a la Administración electrónica son los Criterios de seguridad, normalización y conservación para las aplicaciones utilizadas para el ejercicio de potestades administrativas, que suponen una guía clara de cómo satisfacer en cada momento los requisitos técnicos y jurídicos que pesan sobre el empleo de medios electrónicos, informáticos y telemáticos para el ejercicio de potestades administrativas por parte de la Administración del Estado ${ }^{45}$. La Orden EHA/1307/2005, de 29 de abril, por la que se regula el empleo de medios electrónicos en los procedimientos de contratación, en su dispositivo segundo, declara expresamente la aplicación de estos Criterios a la contratación electrónica realizada por la Administración del Estado.

En esta misma línea, el art.42.2 LAE atribuye al Estado la competencia para aprobar mediante Real Decreto un Esquema Nacional de Seguridad vinculante para todas las Administraciones públicas cuando utilicen medios electrónicos, informáticos y telemáticos, que vendrá sin duda a suceder a los Criterios anteriormente citados en su función de concretar las exigencias de seguridad exigibles a la Administración electrónica.

La Comisión Europea ha orientado a los Estados miembros por lo que se refiere al cumplimiento de requisitos de seguridad, protección de datos, accesibilidad, etc., en materia de contratación electrónica, mediante un documento interpretativo (no vinculante) sólo disponible en versión inglesa ${ }^{46}$.

Por su parte, la Orden de 16 de agosto de 2004, de la Consejera de Hacienda y Administración Pública del País Vasco, sobre tramitación telemática de determinados procedimientos y actuaciones previstas en la legislación de contratos de las Administraciones públicas, concreta en diferentes artículos las exigencias de seguridad, integridad, confidencialidad y conservación en comentario, siendo especialmente destacable el art.16, íntegramente dirigido a regular la forma de evitar la presencia de virus informáticos.

45 Última versión: 2.2 de 24 de junio de 2004, accesible en la web del Consejo Superior para la Administración Electrónica, http://www.csi.map.es, sección "documentos".

${ }^{46}$ Se trata de los Requirements for conducting public procurement using electronic means under the new public procurement Directives 2004/18/EC and 2004/17/EC, SEC(2005) 959, de 8 de julio de 2005; documento no publicado en el Diario Oficial, sólo disponible en versión inglesa y accesible en la URL http://ec.europa.eu/internal_market/publicprocurement/e-procurement_en.htm 


\subsection{La imposición de la firma electrónica reconocida}

La DA 19.1.f) LCSP establece que "Todos los actos y manifestaciones de voluntad de los órganos administrativos o de las empresas licitadoras o contratistas que tengan efectos jurídicos y se emitan tanto en la fase preparatoria como en las fases de licitación, adjudicación y ejecución del contrato deben ser autenticados mediante una firma electrónica reconocida de acuerdo con la Ley 59/2003, de 19 de diciembre, de Firma Electrónica”. Como atinadamente advierte DomínguEz-MACAYA ${ }^{47}$, "esta regulación tiene cuatro características:

a) Se refiere a todos los actos importantes de los expedientes de contratación.

b) Rige tanto para los contratistas como para la propia Administración.

c) Se aplica en todas las fases de la contratación, desde la fase preparatoria hasta la ejecución de los contratos, pasando por la licitación y la adjudicación de los mismos.

d) Al referirse a un procedimientos muy garantista, como es el de la contratación administrativa, el legislador se decanta no por cualquier tipo de firma electrónica, sino por la firma electrónica que da mayores garantías, es decir, la firma electrónica reconocida”.

Como es sabido, la Ley de Firma Electrónica (art.3.3) establece tres tipos de firma electrónica según el grado de sofisticación tecnológica de cada una (firma electrónica a secas, firma electrónica avanzada y firma electrónica reconocida), reconociendo diferentes efectos jurídicos al empleo de cada una de ellas $^{48}$. La variedad más depurada técnicamente es la firma electrónica reconocida, que se basa en un certificado electrónico reconocido, es decir, una herramienta suministrada por un prestador de servicios de certificación, que se instala en un soporte electrónico (disco duro de un ordenador, lápiz óptico...) y que se aplica cada vez que se firma a un documento, momento en el que debe contarse con una conexión telemática, pues en esa operación inter-

${ }^{47}$ Cfr. DOMÍNGUEZ-MACAYA LAURNAGA, J.: “La e-contratación...”, op.cit., p. 2091.

${ }^{48}$ Sobre la cuestión, véanse especialmente CRUZ RIVERO, D.: La firma electrónica reconocida, Madrid, 2006; CERRILLO I MARTÍNEZ, A.; DELGADO GARCÍA, A.M.; GARCÍA ALBERO, J. y PEGUERA POCH, M.: Usos de la firma electrónica en Europa. Panorámica del marco legal y de las aplicaciones prácticas de los certificados digitales en la prestación de servicios de administración electrónica en Europa, Barcelona, 2006; MARTÍNEZ NADAL, A.: Comentarios a la Ley 59/2003, de firma electrónica, Cizur Menor (Navarra), 2004. 
viene un tercero de confianza o notario digital (el prestador de servicios de certificación que suministró el certificado), el cual acredita que el firmante suscribe el documento en cuestión. Esta modalidad de firma electrónica goza del máximo valor jurídico, pues el art.3.4 LFE reconoce a los datos consignados en forma electrónica mediante este concreto tipo de firma el mismo valor que la firma manuscrita respecto de los datos consignados en papel. Como hemos podido leer en la transcripción inicial, la DA 19 LCSP impone el uso de este concreto tipo de firma electrónica tanto a los órganos administrativos como a las empresas licitadoras o contratistas.

El empleo de la firma electrónica en materia de Administración electrónica ha recibido una regulación muy rica y perfectamente estructurada en la Ley 11/2007 -arts.13 y sigs.-, tanto en lo que se refiere a su uso por los órganos administrativos ${ }^{49}$, como por los ciudadanos ${ }^{50}$. Este texto es mucho más versátil en la regulación de los tipos de firma electrónica admisibles en el tráfico jurídico-administrativo, permitiendo que cada Administración pública decida el tipo de firma exigible según el concreto ámbito en que se actúe en cada momento. Un claro ejemplo del juego que depara la LAE lo encontramos en el Decreto del Gobierno Vasco 232/2007, de 18 de diciembre, por el que se regula la utilización de medios electrónicos, informáticos y telemáticos en los procedimientos administrativos: esta disposición -arts.11 y sigs., y DA 2gradúa el tipo de firma electrónica necesario para diferentes categorías de procedimientos administrativos, no imponiendo necesariamente la firma electrónica reconocida para todas las actuaciones que se realicen.

A mi juicio, y a diferencia de lo que opina Domínguez-MACAYA ${ }^{51}$ la LCSP ha sido excesivamente exigente en este punto, limitando de manera inoportuna las opciones que podrían haber articulado las Administraciones públicas en esta cuestión: por ejemplo, la creación de entornos cerrados de comunicación entre la Administración y los licitadores o contratistas, dotados de otros

\footnotetext{
${ }^{49}$ En relación con el tema, véase LINARES GIL, M.: "Identificación y autenticación de las Administraciones públicas", en GAMERO CASADO, y VALERO TORRIJOS, J. (coords.): La Ley de Administración electrónica, op.cit., págs. 281 y sigs.

${ }^{50}$ Véase sobre esta cuestión MARTÍN DELGADO, I.: "Identificación y autenticación de los ciudadanos", en GAMERO CASADO, y VALERO TORRIJOS, J. (coords.): La Ley de Administración electrónica, op.cit., págs. 317 y sigs.

${ }^{51}$ Véase DOMÍNGUEZ-MACAYA LAURNAGA, J.: "La e-contratación”, en VV.AA.: Contratación del sector público local, La Ley-El Consultor, Madrid, 2008, pp. 2091 ss. y 2235 ss.
} 
sistemas de autenticación, alternativa claramente ventajosa en ciertos procedimientos específicos, como los sistemas dinámicos de contratación, en los que las comunicaciones tienen lugar con un concreto número de interesados y no con la ciudadanía en general ${ }^{52}$.

A los particulares, esta determinación normativa no les resultará onerosa, pues en España se suministra gratuitamente el DNI electrónico, provisto de un certificado electrónico reconocido, que ha de ser además necesariamente admitido por todas las Administraciones públicas -arts.13.2 a) y 14 LAE-. Por el contrario, la opción legal resulta gravosa para las Administraciones públicas, y en especial las de dimensiones modestas, pues el desarrollo de los sistemas y aplicaciones aptos para soportar comunicaciones con firma electrónica reconocida son muy costosos. El esfuerzo presupuestario no será relevante para las grandes Administraciones, cuyas compras masivas amortizarán estas inversiones, pero sí complica el panorama a entidades de dimensiones modestas, las cuales habrán de procurar la reutilización de aplicaciones ya desarrolladas y cedidas por otras Administraciones públicas, o bien la articulación de fórmulas de concertación con otras entidades para el desarrollo conjunto de estos sistemas; importa notar, en este sentido, el papel que pueden desempeñar las Diputaciones Provinciales dando soporte a sistemas de contratación electrónica de los municipios y entidades dependientes de los mismos.

De otro lado, esta exigencia impuesta por la DA 19 LCSP es incoherente con la DA 18 del propio cuerpo legal, que resulta más flexible en relación con las técnicas que garanticen la identidad y la integridad en las comunicaciones telemáticas realizadas en materia de contratación administrativa, pues establece de modo genérico que "Las comunicaciones, los intercambios y el almacenamiento de información se realizarán de modo que se garantice la protección de la integridad de los datos y la confidencialidad de las ofertas y de las solicitudes de participación, así como que el contenido de las ofertas y de las solicitudes de participación no será conocido hasta después de finalizado el plazo para su presentación o hasta el momento fijado para su apertura", requisitos que no sólo pueden verse satisfechos con la firma electrónica reconocida, sino también con la firma electrónica avanzada.

La disonancia entre ambos textos legales puede provenir del diferente origen de cada una de las Disposiciones Adicionales en comentario: la DA 18

\footnotetext{
52 Otras soluciones para este mismo problema en HERNÁNDEZ, E.: "Simplificando trámites. La licitación pública por medios electrónicos”, Bole.tic, nº 28, 2003, pág. 62.
} 
transcribe de forma prácticamente literal el art.42 de la Directiva 2004/18/CE, a la que traspone; en tanto que la DA 19 procede de la Orden EHA/1307/2005, siendo asimismo transcripción literal de su apartado Cuarto.Dos. El conflicto normativo puede resolverse entendiendo que la DA 19.1.f) LCSP, por ser en este punto de contenido más específico, desplaza en su aplicación a la DA 18, siendo pues exigible la firma electrónica reconocida en los términos establecidos en aquélla. Pero conviene destacar que la exigencia no deriva tampoco del Derecho comunitario, como se ve, más flexible que la LCSP en este punto, pues incluso promueve el uso de la firma electrónica avanzada (no la reconocida) en el art.42.5b) de la Directiva 2004/18/ $\mathrm{CE}^{53}$; de hecho, GALLEGO ha advertido que la Comisión Europea muestra reparos a la imposición de la firma electrónica reconocida en materia de contratación administrativa debido a que puede suponer un obstáculo real y persistente para la contratación electrónica transfronteriza ${ }^{54}$.

\section{OTRAS REGLAS GENERALES EN LA CONTRATACIÓN ELEC- TRÓNICA}

\subsection{Incidencias en la presentación de documentos}

La DA 19.1 g) LCSP establece que "Los licitadores o los candidatos deberán presentar los documentos, certificados y declaraciones que no estén disponibles en forma electrónica antes de que expire el plazo previsto para la presentación de ofertas o de solicitudes de participación”. Se sobreentiende que esa presentación habrá de hacerse en soporte papel y por los cauces tra-

${ }^{53}$ Cuyo texto es el siguiente: "Para los dispositivos de transmisión y recepción electrónica de las ofertas y los dispositivos de recepción electrónica de las solicitudes de participación se aplicarán las normas siguientes: (...) b) Con arreglo al artículo 5 de la Directiva 1999/93/CE (LCEur\2000\85), los Estados miembros podrán exigir que las ofertas transmitidas por vía electrónica vayan acompañadas de una firma electrónica avanzada de conformidad con lo dispuesto en el apartado 1 de dicho artículo". A mayor abundamiento, el considerando 37 de la Exposición de Motivos de la Directiva señala que: "Los procedimientos de adjudicación de contratos públicos y las normas aplicables a los concursos de proyectos exigen un nivel de seguridad y confidencialidad superior al requerido por dichas Directivas. Por consiguiente, los instrumentos para la recepción electrónica de ofertas, solicitudes de participación, así como planes y proyectos, deben cumplir unos requisitos adicionales específicos. A estos efectos, debe fomentarse, en la medida de lo posible, el uso de firmas electrónicas, en especial las firmas electrónicas avanzadas".

${ }^{54}$ Véase GALLEGO CÓRCOLES, I.: “Contratación pública electrónica”, op.cit., pág. 251. 
dicionales. Determinaciones de este tipo han sido reprochadas por MES$\mathrm{TRE}^{55}$, quien estima que suponen un retraso innecesario en la gestión del procedimiento de contratación, siendo preferible centralizar la información en soporte digital en instituciones, órganos o poderes adjudicadores concretos, articulando cruces telemáticos de datos mediante la interconexión de las redes respectivas ${ }^{56}$. De este modo, los datos obrantes en un determinado Registro de contratistas podrían aportarse de oficio y de forma telemática a las licitaciones que el mismo presente ante otro poder adjudicador diferente.

Otra alternativa digna de mención es la digitalización del documento en papel, y su presentación por vía telemática ${ }^{57}$, evitando así además la existencia de un mismo expediente en dos soportes distintos. El primer inciso de la DA 19.1.h) LCSP admite expresamente esta posibilidad.

Esa misma letra resuelve un importante problema que puede plantearse con ocasión de la presentación de ofertas en la adjudicación de los contratos, estableciendo que: "En los procedimientos de adjudicación de contratos, el envío por medios electrónicos de las ofertas podrá hacerse en dos fases, transmitiendo primero la firma electrónica de la oferta, con cuya recepción se considerará efectuada su presentación a todos los efectos, y después la oferta propiamente dicha en un plazo máximo de 24 horas; de no efectuarse esta segunda remisión en el plazo indicado, se considerará que la oferta ha sido retirada”. Esta previsión no se contenía en el Anteproyecto, y constituye una mejora auspiciada por DOMÍNGUEZ-MACAYA ${ }^{58}$. Resuelve la eventualidad de que un interesado intente presentar su oferta y se encuentre con problemas que lo impidan: fallos en la conexión, aportación de ficheros extraordinariamente extensos (como es propio en la presentación de planos, por ejemplo)

${ }^{55}$ Véase MESTRE DELGADO, J.F.: “La subasta...”, op.cit., págs. 24 y sig.

56 Una opción claramente impulsada por el art.43 LAE, y que viene aplicándose en ámbitos sectoriales específicos donde cosecha grandes éxitos: por ejemplo, la AEAT ha tendido muchas pasarelas con diferentes instituciones para el cruce de datos fiscales.

57 Sirva de ejemplo en esta cuestión la Resolución AEAT de 24 de octubre de 2007 sobre homologación de software para digitalización de facturas.

${ }^{58}$ En los diferentes trabajos de comentario al Anteproyecto de Ley que publicó en diferentes revistas especializadas; véase, en particular, DOMÍNGUEZ-MACAYA LAURNAGA, J.: "La contratación electrónica...”, op.cit., págs. 68 y sigs. 
que sean bloqueados por el servidor o que prolonguen extensamente el período de conexión provocando disfunciones, etc. La solución adoptada por la LCSP se inspira en el Derecho francés, y se corresponde linealmente con la propuesta del autor citado.

Por último, la propia DA 19.1.h) in fine LCSP establece que "Las copias electrónicas de los documentos que deban incorporarse al expediente, autenticadas con la firma electrónica reconocida del órgano administrativo habilitado para su recepción surtirán iguales efectos y tendrán igual valor que las copias compulsadas de esos documentos". Esta previsión resulta superflua por corresponderse linealmente con el art.30 de la Ley 11/2007, aplicable en materia de contratación electrónica como sostuve en su lugar ${ }^{59}$.

\footnotetext{
${ }^{59}$ Un artículo, por otra parte, mucho más acertado en su contenido, que bajo la rúbrica "Copias electrónicas", es el siguiente:

1. Las copias realizadas por medios electrónicos de documentos electrónicos emitidos por el propio interesado o por las Administraciones Públicas, manteniéndose o no el formato original, tendrán inmediatamente la consideración de copias auténticas con la eficacia prevista en el artículo 46 de la Ley 30/1992, de Régimen Jurídico de las Administraciones Públicas y del Procedimiento Administrativo Común, siempre que el documento electrónico original se encuentre en poder de la Administración, y que la información de firma electrónica y, en su caso, de sellado de tiempo permitan comprobar la coincidencia con dicho documento.

2. Las copias realizadas por las Administraciones Públicas, utilizando medios electrónicos, de documentos emitidos originalmente por las Administraciones Públicas en soporte papel tendrán la consideración de copias auténticas siempre que se cumplan los requerimientos y actuaciones previstas en el artículo 46 de la Ley 30/1992, de Régimen Jurídico de las Administraciones Públicas y del Procedimiento Administrativo Común.

3. Las Administraciones Públicas podrán obtener imágenes electrónicas de los documentos privados aportados por los ciudadanos, con su misma validez y eficacia, a través de procesos de digitalización que garanticen su autenticidad, integridad y la conservación del documento imagen, de lo que se dejará constancia. Esta obtención podrá hacerse de forma automatizada, mediante el correspondiente sello electrónico.

4. En los supuestos de documentos emitidos originalmente en soporte papel de los que se hayan efectuado copias electrónicas de acuerdo con lo dispuesto en este artículo, podrá procederse a la destrucción de los originales en los términos y con las condiciones que por cada Administración Pública se establezcan.

5. Las copias realizadas en soporte papel de documentos públicos administrativos emitidos por medios electrónicos y firmados electrónicamente tendrán la consideración de copias auténticas siempre que incluyan la impresión de un código generado electrónicamente u otros sistemas de verificación que permitan contrastar su autenticidad mediante el acceso a los archivos electrónicos de la Administración Pública, órgano o entidad emisora.
} 


\subsection{El formato de los documentos presentados}

La DA 19.1.i) LCSP dispone que "Los formatos de los documentos electrónicos que integran los expedientes de contratación deberán ajustarse a especificaciones públicamente disponibles y de uso no sujeto a restricciones, que garanticen la libre y plena accesibilidad a los mismos por el órgano de contratación, los órganos de fiscalización y control, los órganos jurisdiccionales y los interesados, durante el plazo por el que deba conservarse el expediente. En los procedimientos de adjudicación de contratos, los formatos admisibles deberán indicarse en el anuncio o en los pliegos". Esta previsión atiende a otro importante problema en materia de gestión electrónica: la interoperabilidad de los formatos de documentos utilizados por diferentes partes en sus relaciones recíprocas.

Es perfectamente posible que un licitador o un contratista utilice para crear sus documentos programas que la Administración no maneje, bien porque sean obsoletos, o al contrario, porque sean excesivamente avanzados. Si la cuestión no recibe regulación expresa, se siembra la duda acerca del tipo de documentos que se pueden enviar a la Administración, o en otras palabras, si ésta tiene el deber de aceptar cualquier formato o bien puede restringir los admitidos a un cuadro cerrado de opciones que condicionan correlativamente las alternativas de los ciudadanos.

La opción seguida por la LCSP es sentar unas reglas generales sobre las condiciones que, en línea de principio, han de reunir los documentos: adaptarse a especificaciones públicamente disponibles y no sujetas a restricciones, etc. Y una acotación específica: cuando se trata de la adjudicación de los contratos, los formatos admisibles deberán indicarse en el anuncio o en los pliegos. Se ha reprochado la excesiva ambigüedad de esta regulación ${ }^{60}$, y en efecto, otras disposiciones de interés concretan de mejor manera los formatos de documentos admisibles, siendo especialmente significativo el caso de la Orden de 16 de agosto de 2004, de la Consejera de Hacienda y Administración Pública del País Vasco -citada-, cuyo art.15.1 establece en relación con esta cuestión "Los formatos admisibles son los siguientes: .doc, .xls, .ppt, .pdf, .rtf, .sxw, .abw, .jpg, .bmp, .tiff, .zip y .7z", y el 15.3 puntualiza que "Con el objetivo de minimizar en lo posible la incidencia que la presencia de virus contemplada

60 Véase DOMÍNGUEZ-MACAYA LAURNAGA, J.: "La contratación electrónica...", op.cit., págs. 69 y sigs. 
en el artículo siguiente pueda tener en la operatividad de las ofertas enviadas, se recomienda el envío de las mismas en los formatos .pdf, .rtf, .sxw, .jpg y .tiff". Por otra parte, la Orden EHA/1307/2005, determina en su Anexo los concretos formatos de documentos admisibles en la contratación electrónica.

La cuestión no es menor, pues en materia de contratación administrativa, por la complejidad que muchas veces entraña la preparación de los proyectos, resulta perfectamente posible que el licitador o el contratista utilicen programas informáticos exclusivos (creados por ellos mismos) o de alta tecnología, de los que puede carecer la Administración. Por ello, habría sido preferible un mayor grado de concreción en la acotación de los formatos admisibles, que si bien no es procedente abordar en la propia Ley para no congelar el rango de la disposición complicando su actualización con arreglo a los avances de la técnica, sí podía haberse remitido perfectamente a desarrollo reglamentario.

Por otra parte, interesa destacar que el formato ".pdf 1.7" -portable document format - ha logrado el máximo reconocimiento de normalización mundial habiéndose convertido en la norma ISO 32000 Standard (DIS) ${ }^{61}$, tras haber cedido la empresa creadora su código fuente y convertirse en formato de fuentes abiertas. El formato no sólo es muy versátil y admite la conversión de otros muchos archivos, sino que además garantiza la integridad del documento convertido, pues cualquier cambio ulterior deja traza. Por ello, su uso está muy generalizado tanto en el ámbito privado como en el público, e incluso es muy frecuente que la Administración dicte actos en soporte papel, escanee y digitalice su imagen, y los convierta luego a ese formato para su envío telemático.

\subsection{Inscripción obligatoria de datos en el Registro Oficial de Licitadores y Empresas Clasificadas}

El art.303.1 LCSP establece los datos que se podrán inscribir en el Registro Oficial de Licitadores y Empresas Clasificadas, convirtiendo esta inscripción en potestativa. La DA 19.1.j) LCSP establece que "Como requisito para la tramitación de procedimientos de adjudicación de contratos por medios electrónicos, los órganos de contratación podrán exigir a los licitadores la previa inscripción en el Registro Oficial de Licitadores y Empresas Clasificadas que corresponda de los datos a que se refieren las letras a) a d) del artículo 303.1",

\footnotetext{
${ }^{61}$ El grupo de trabajo internacional sobre esta norma ISO adoptó la decisión definitiva en su reunión de Orlando, los días 21-23/1/2008.
} 
pudiendo por tanto imponerse la inscripción de estos datos para poder participar en la licitación por medios electrónicos. Hay que poner esta previsión en conexión con el art.72.1 LCSP, que reconoce valor probatorio a las certificaciones de los datos obrantes en el Registro, admitiéndose, además, que dichas certificaciones se expidan por medios electrónicos -art.72.2-, de modo que esta certificación puede obtenerse mediante un simple cruce telemático de datos entre el Registro y el órgano contratante. Sabido esto, es llano que la previsión de la DA 19.1.j) LCSP pretende lograr una mayor agilidad en la tramitación del procedimiento, pues al poderse imponer a los licitadores la previa inscripción de estos datos en el Registro, y articularse después la certificación por medios telemáticos, se logra un considerable ahorro de tiempo y gestiones.

Sin embargo, no ha llegado a preverse expresamente la inscripción en el Registro de otros datos (como por ejemplo, el cumplimiento de las obligaciones tributarias y de cotización a la Seguridad Social), como había sido propuesto durante la tramitación del Proyecto de Ley ${ }^{62}$.

Para concluir, remito el análisis de la DA 19.2 LCSP a lo que inmediatamente comentaré acerca de la DF 9, con la que guarda estrecha relación.

\section{LA FACTURA ELECTRÓNICA}

La Disposición final 9 ${ }^{\mathrm{a}}$ LCSP pretende claramente extender la utilización de la factura electrónica en la contratación del sector público, estableciendo una serie de determinaciones dirigidas a definir el modo en que se concretarán sus requisitos, y estableciendo una serie de pautas para la progresiva generalización de este tipo de facturación, convirtiéndola en obligatoria en plazos sucesivos (entre 15 y 30 meses desde la entrada en vigor de la Ley). Poco cabe añadir a lo que se desprende directamente de la interpretación literal del texto acerca de los plazos y diferentes universos de sujetos progresivamente obligados a la utilización de la factura electrónica hasta su total implantación. Tales previsiones son las siguientes:

«3. En el plazo máximo de un año desde la entrada en vigor de la Ley, el Ministro de Economía y Hacienda aprobará las normas de desarro-

\footnotetext{
${ }^{62}$ Véase DOMÍNGUEZ-MACAYA LAURNAGA, J.: "La contratación electrónica...”, op.cit., pág. 70.
} 
llo necesarias para hacer posible el uso de las facturas electrónicas en los contratos que se celebren por las entidades del sector público estatal.

«4. Transcurridos tres meses desde la entrada en vigor de las normas a que se refiere el apartado anterior la presentación de facturas electrónicas será obligatoria en la contratación con el sector público estatal para las sociedades que no puedan presentar cuenta de pérdidas y ganancias abreviada.

Por Orden conjunta de los Ministros de Economía y Hacienda y de Industria, Turismo y Comercio, se extenderá progresivamente la obligatoriedad del uso de las facturas electrónicas para otras personas físicas y jurídicas en función de sus características y el volumen de su cifra de negocios. En todo caso, transcurridos dieciocho meses desde la entrada en vigor de las normas a que se refiere el apartado anterior, el uso de la factura electrónica será obligatorio en todos los contratos del sector público estatal; no obstante, en los contratos menores, la utilización de la factura electrónica será obligatoria cuando así se establezca expresamente en estas Órdenes de extensión.

«5. El Consejo de Ministros, a propuesta de los Ministros de Economía y Hacienda y de Industria, Turismo y Comercio, adoptará las medidas necesarias para facilitar la emisión de facturas electrónicas por las personas y entidades que contraten con el sector público estatal, garantizando la gratuidad de los servicios de apoyo que se establezcan para las empresas cuya cifra de negocios en el año inmediatamente anterior y para el conjunto de sus actividades sea inferior al umbral que se fije en la Orden a que se refiere el párrafo anterior».

Esta materia guarda estrecha conexión con la Orden EHA/962/2007, de 10 de abril, por la que se desarrollan determinadas disposiciones sobre facturación telemática y conservación electrónica de facturas, contenidas en el Real Decreto 1496/2003, de 28 de noviembre, por el que se aprueba el reglamento por el que se regulan las obligaciones de facturación; disposición que, a su vez, ha sido desarrollada por la Resolución de 24 de octubre de 2007, de la Agencia Estatal de Administración Tributaria, sobre procedimiento para la homologación de software de digitalización contemplado en la Orden EHA/962/2007, de 10 de abril de 2007.

En cualquier caso, el más claro precedente en la materia viene representado por la Orden PRE/2971/2007, de 5 de octubre, sobre la expedición de facturas por medios electrónicos cuando el destinatario de las mismas sea la Administración General del Estado u organismos públicos vinculados o de- 
pendientes de aquélla y sobre la presentación ante la Administración General del Estado o sus organismos públicos vinculados o dependientes de facturas expedidas entre particulares.

La inspiración para adoptar la imposición obligatoria de la factura electrónica en la contratación pública procede del Derecho danés, donde este régimen juega desde el 1 de enero de 2005, ahorrando 150 millones de euros a las arcas públicas y 50 millones a las empresas ${ }^{63}$.

Es de significar, por otra parte, que el art.1 de la Ley 56/2007, de 28 de diciembre, de medidas de impulso de la sociedad de la información, recuerda expresamente que "La facturación electrónica en el marco de la contratación con el sector público estatal será obligatoria en los términos que se establezcan en la Ley reguladora de la contratación en el sector público y en su normativa de desarrollo", y añade, además, que "A estos efectos, se entenderá que la factura electrónica es un documento electrónico que cumple con los requisitos legal y reglamentariamente exigibles a las facturas y que, además, garantiza la autenticidad de su origen y la integridad de su contenido, lo que impide el repudio de la factura por su emisor". La primera de estas previsiones es redundante con lo que, de suyo, deriva ya de la Disposición Final 19a LCSP, y su sentido parece ser el incorporar esta advertencia a una ley más familiar para el sector privado, que ha podido tomar en consideración la necesidad de trasladar este precepto a los pequeños contratistas (piénsese, por ejemplo, en suministros modestos pero muy frecuentes, o en obras menores, y tantos otros ámbitos de la contratación pública en los que la LCSP prácticamente queda inédita y por tanto es completamente ajena a los contratistas), para que lo tengan presente en sus relaciones con la Administración y vayan acomodando la dotación de sus empresas a fin de atender esta nueva exigencia en un futuro próximo.

A este objetivo cautelar la Ley 56/2007 añade una definición de la factura electrónica que no aparece en la LCSP, y que constituye, por tanto, una verdadera aportación normativa. Sin embargo, el texto es poco preciso y utiliza unas menciones absolutamente previsibles: autenticidad, integridad y no repudio. Se trata, por otra parte, de exigencias que ya hemos analizado en el comentario a la DA 19 (§2.5), al que remito para mayores precisiones sobre este particular.

${ }^{63}$ Son los datos que aporta DOMÍNGUEZ-MACAYA LAURNAGA, J.: "La contratación electrónica en el Proyecto de Ley de Contratos del Sector Público. Análisis y propuestas de mejora", Contratación administrativa práctica, $\mathrm{n}^{\circ} 62,2007$, págs. 64 y sigs. 
Conviene notar, no obstante, que la Orden PRE/2971/2007, de 5 de octubre -ya citada- incorpora algunas determinaciones que podrían mantenerse en el futuro desarrollo reglamentario de la cuestión. En particular, dicho texto -art.4- establece que la firma electrónica exigible para la expedición de estas facturas ha de ser cuando menos una firma electrónica avanzada (no llega a exigir la firma reconocida como hace la LCSP), ajustada a la especificación XML-Advanced Electronic Signatures (XAdES), ETSI TS 101903.

Por otra parte, el Ministerio de Industria, Turismo y Comercio mantiene un portal sobre la facturación electrónica (pública y privada) accesible en la URL http://www.facturae.es . El art.5 de la Orden en examen declara que, a través de dicho portal, el Ministerio pondrá a disposición de los usuarios las herramientas necesarias para asegurar la convertibilidad y compatibilidad del formato establecido en la Orden y de aquél o aquéllos que surjan como evolución del formato de factura electrónica. Por consiguiente, la consulta de este portal será de utilidad realizar un seguimiento de la cuestión.

\section{CONCLUSIÓN}

En un mundo como el actual, que ha modificado radicalmente sus relaciones para colocar las telecomunicaciones en el centro de la vida económica, social y cultural, la contratación electrónica constituye un campo muy necesitado de impulso material ${ }^{64}$ y regulación jurídica. La Ley 30/2007 defrauda sin paliativos las expectativas que pudo suscitar en punto a conferir a esta materia un régimen acorde con las Directivas comunitarias de referencia, con el acervo jurídico ya acuñado en nuestro Derecho y con el grado real de implantación de las tecnologías de la información y la comunicación en nuestro tejido empresarial. Más a más, el lugar sistemático elegido para abordar esta cuestión carece de toda visión estratégica, situando a la contratación electrónica en el cuarto trastero de la Ley, donde menos lucen sus preceptos y donde nadie diría que se encierra una regulación sobre la que en los próximos años girará un tráfico jurídico y comercial tan relevante.

\footnotetext{
${ }^{64}$ Para conocer sabios consejos acerca de "Cómo llevar a cabo un proyecto de ie-contratación" (contratación electrónica integral), véase la aportación del mismo título realizada por DOMÍNGUEZ-MACAYA LAURNAGA, J.: "La e-contratación...”, op.cit., pp. 2295 ss., donde se exponen sistemática y minuciosamente los condicionamientos técnicos y organizativos de la contratación electrónica y el modo de desarrollar un proyecto de implantación integral de contratación electrónica.
} 
Pero por más que la Ley sea desafortunada en la elección del lugar y en los contenidos materiales de la regulación, me parece indudable que la contratación electrónica, de aquí a unos pocos años, representará un porcentaje elevadísimo de la actividad administrativa en materia de contratación (baste percibir el impacto que representará la imposición obligatoria de la factura electrónica), y por consiguiente, es de lamentar esta inexplicable miopía del legislador.

Los desarrollos materiales que todas las Administraciones públicas están llevando a cabo de la cuestión (primordialmente, la Administración General del Estado y de las Comunidades Autónomas) no se corresponden en modo alguno con este ninguneo normativo, y ponen en evidencia la extraordinaria facilidad con la que se puede implantar la contratación electrónica y el uso masivo que cabe hacer de ella. La generalizada publicación de los perfiles de contratante, la implantación de los registros telemáticos de contratistas, la puesta en marcha de la plataforma de contratación del Estado y su interconexión telemática con los diarios oficiales a efectos de inserción de anuncios (cuestiones todas más visibles que los asuntos que hemos tratado en este trabajo), o el ya habitual recurso a las subastas electrónicas, evidencian la rapidez e intensidad de los cambios habidos en este campo. Ahora, la reutilización de las aplicaciones utilizadas para la puesta en marcha de estos servicios, así como nuevas aplicaciones que irán surgiendo de cara a la generalización de la factura electrónica y otras utilidades de Administración electrónica específicamente aplicadas a la contratación, supondrán un cambio radical en el cauce de gestión de la contratación administrativa que, por desgracia, no se verá correspondido con una legislación a la altura de las circunstancias. 